\title{
Multicultural Educational Practices: School Women Leaders Perspectives And Contextual Realities For Promoting Intercultural Harmony In Schools
}

\author{
Tayyaba Zarif \\ Department of Education \\ Newports Institute of Communication and Economics \\ $\&$ \\ Aziz -un -Nisa \\ Department of Education \\ University of Karachi
}

\begin{abstract}
The increasing diversity of cultural, ethnic, racial and tribal composition of societies in general and schools in particular signify the importance of multicultural education at all levels of education. In this context the roots of such a concept can be strengthened at school level in any community. Here the role of school leadership is imperative towards promoting intercultural harmony in the school environment in general and the curriculum and classroom practices in particular. This research sheds light on the perspectives of school leadership and the actual scenarios at school level to integrate intercultural education into mainstream curriculum and teaching-learning practices at schools. For this reason altogether 30 School leaders were selected through purposive-random sampling from a sample of 30 private schools of Karachi selected with the help of convenient sampling. The most experienced School leaders were selected for this study. The perspective of School leadership regarding Multicultural Education and their practices in everyday schooling was collected through interviews by using an open ended questionnaire so the study is completely qualitative in nature. The theme analysis of qualitative data was done. The theme analysis depicts that the principals in-general seem to possess a positive understanding of multicultural education and that they preferred a very neutral approach for multicultural education.

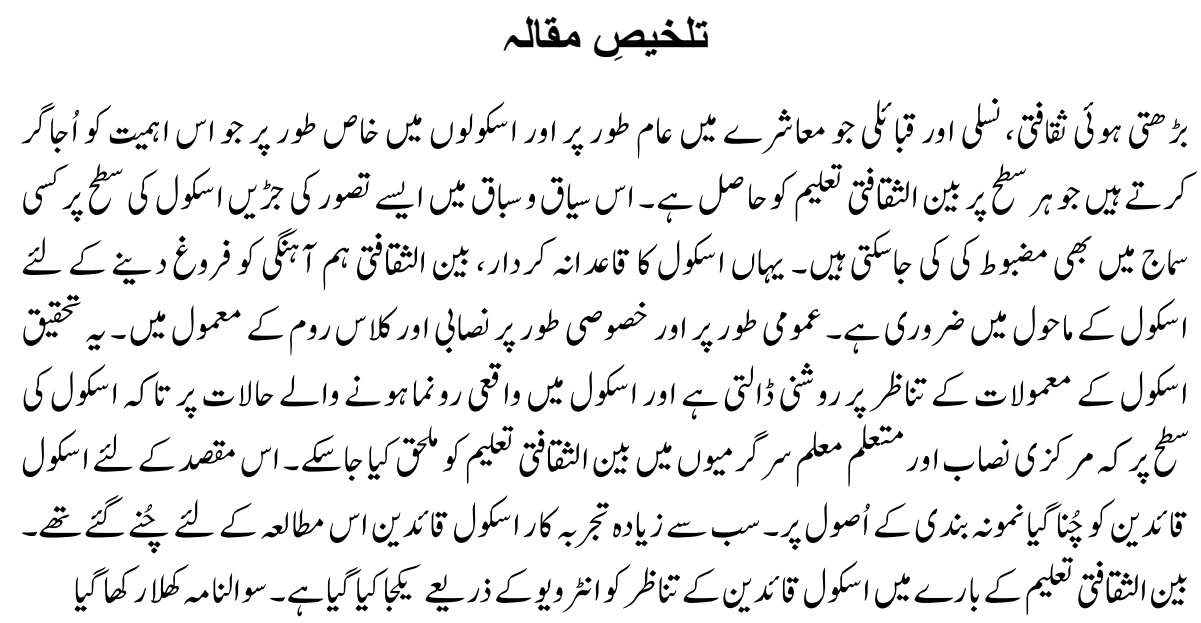


100 Multicultural Educational Practices: School Women Leaders Perspectives and Contextual Realities for Promoting Intercultural Harmony in Schools

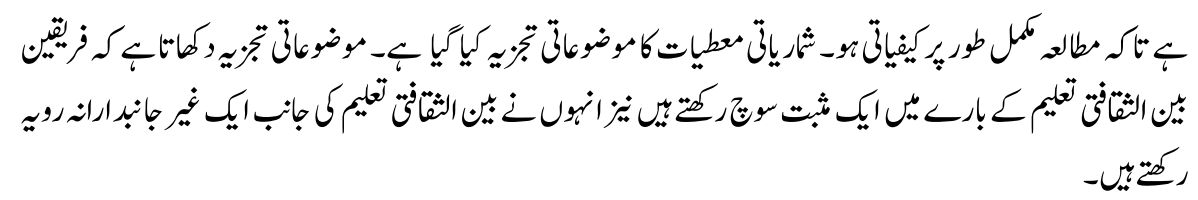

Key Words: School Women leadership, perception, Multicultural Education, School practices

\section{Introduction and Literature Review}

Linguistically, the word "culture" is derived from the Latin verb colere, meaning to cultivate, inhabit or honour. The word evolved to mean the outline of human activities, counting the "usual beliefs, social forms and material qualities .Culture is fundamentally a framework for behavior.

Ploumis- Devick expresses a view which is gaining wide spread currency when she writes:

...... Culture is basically a framework for behavior. It consists of human-made guidelines, written and unwritten, that serve to provide order to how groups of people relate to one another and to their world. Cultural diversity refers simply to the differences which exist among cultural groups (1992, p. 6).

Culture is actually a charter of human behavior, an outline or agenda that is followed to relate humans worldwide. These charters can be similar or subject to diversity depending upon many factors. These cultural diversities pertain among all the groups.

This definition is helpful, because of its broad conception of culture. And, indeed, much of the recent research and other writing on intercultural relations and multicultural education has gone beyond issues of race and ethnicity (which tend to come to mind first when thinking of culture) to include other groups that have been targets of prejudice and discrimination.

Researchers Sleeter and Grant write:

Originally linked only to concerns about racism in schooling, [multi-cultural education] has expanded to address sexism, classism, and handicapism (1987, p.421).

Sleeter and Grant wrote that cultural diversity were traditionally linked to multi-cultural education only in educational organizations which has increased its horizon to sexism, classism, and handicapism. 
There have been many demographic changes in cultural aspects these demographic changes, influencing education system time to time so there is a need to incorporate an essence of intercultural harmony in our learning foundations.

Intercultural education, according to the National Council for Curriculum and Assessment ("NCCA") (2006: i), has the following defining characteristics:

- It is education which respects, celebrates and recognises the normality of diversity in all areas of human life. It sensitises the learner to the idea that humans have naturally developed a range of different ways of life, customs and worldviews, and that this breadth of human life enriches all of us.

- It is education, which promotes equality and human rights, challenges unfair discrimination, and promotes the values upon which equality is built.

The contextual realities of educational systems prevalent around us ascertain that there is a need to incorporate an essence of intercultural harmony in our learning institutions. In this regard, a global change of the very structure, practices and the educational culture itself constitute a viable way forward towards a more inclusive and intercultural approach towards professional development of learners and community involvement as the core focus of state policies (Kincheloe \& Steinberg, 1997).

Even in the international scenario there is not adequate presence of an inclusive educational system. Even in stable and prosperous states like Spain, there is little convention as far as inter culturally inclusive teaching practice is concerned for good teaching practices (Sales \&García, 1997).

The very concept of intercultural education advocates that differences are positive and enriching when conditions of social justice are taken care and the differences are not in equal.

Inducing an intercultural environment at school and opening it to diversity is therefore a job of a leader that takes up the role of a reflective practitioner. The training programmes that take place in the school for teachers' professional development should entail the objectives of evolving skills of action and reflection, knowledge sharing and management, attitudes and skills for identification of the roles of school heads and teachers as reflective practitioners. Such programmes can also encompass crosscultural themes based on communications, democratic participation, decision-making and cooperative work (Darling-Hammond, 2006).

Writing about intercultural relations in schools, Parrenas and Parrenas note that:

...the problem of poor race relations among students is progressive: each school year students choose fewer friends outside their own ethnic or cultural 
102 Multicultural Educational Practices: School Women Leaders Perspectives and Contextual Realities for Promoting Intercultural Harmony in Schools

group....by the end of elementary school they begin to segregate themselves along race lines. Racial divisions and tensions increase through middle school, culminating by high school in students isolated from those in other racial groups. Whether or not there is the appearance of racial gangs, there is racial tension (1990, pp. 7-8).

According to Parrenas and Parrenas that this menace of racial tension generate with time among the students as they progress from their each school level that is from their first days till the end of high school. With the passage of time, from making friends beyond their ethnic and racial group they divide themselves along racial lines, so much so that they get isolated from those who are in other racial groups.

Towards developing a better understanding of the concept of multiculturalism and the dimensions of multicultural education varied definitions by numerous scholars and researchers can be taken into account. Following are some examinations of existing definitions that have been taken into account for the context of this study. This analysis is important because it gives a theoretical base for this study. According to Bennett (2003);

"Multicultural Education is an approach to teaching and learning that is based upon democratic values and beliefs and that affirms cultural pluralism within culturally diverse societies in an interdependent world” (p.14).

Multi-cultural education system is based on the autonomous governing rules which upholds the cultural togetherness and reduces the diversities among societies.

Gorski's (2001) definition of multicultural education provided a strong foundation on which curriculum should be developed;

"Multicultural education is a transformative movement in education that produces critically thinking, socially active members of society. It is not simply a change of curriculum or the addition of an activity. It is a movement that calls for new attitudes, new approaches, and a new dedication to laying the foundation for the transformation of society" (p.1).

Multi-cultural approach towards education promotes and encourages new attitudes, new approaches and a ground firming approach for the transformation of society to build a less diversified society.

Banks (1999) suggested a parallel view:

"Multicultural education is an idea, an educational reform movement, and a process whose major goal is to change the structure of educational institutions so that male and female students, exceptional students, and students who are 
members of diverse, racial, ethnic and cultural groups will have an equal chance to achieve academically in school" (p.1).

Banks suggested an alternate view to it and says that multi-cultural education system is a course whose major aim is to gather students from diverse racial, ethnic and cultural groups and as well belonging to different genders.

Nieto (2000) describes multicultural education as a process of reforming a school and it is for all stakeholders especially the students. It infuses the entire curricula including the school organization. According to Sleeter and Grant (1988), the multicultural education is not a subject matter but it is education itself.

Arguing for an even broader view of multi-cultural education, University of Washington Multicultural Education Center Director, James Banks, writes:

A lot of people are on the margins of society because of their race, class, gender, or sexual orientation. Multi-cultural education is about bringing them to the center, making one nation from many people. That is consistent with the nation's motto, "E Pluribus Unum" (quoted in Lockwood 1992, p. 7).

According to Bank (1997), multicultural education can be ensured with the presence of content integration, process of knowledge construction, neutrality, equity pedagogy, social and school culture that is empowering at its core. However, all of the mentioned elements are essentially integrated and considerable attention is required on each of them.

In this pretext the recurring similarities in all the definitions can be summed up with a deduction that multicultural education is a process and a transformative movement that literally brings about 'change'. In order to develop educational equity at different levels and to ensure social justice, the concept and content of multicultural education should be infused not only into the school curricula but should be reflected in each and every practice or function related to teaching and learning of a school.

Multicultural educators seek to substantially restructuring schools to give various students an equal chance in school, in the job market, and in contributing to building healthy communities (Bank,2008).

Today, teachers in the majority urban areas face students from a variety of social classes and cultural and language groups Multiculturalism focus on the idea that students and their backgrounds and experiences should be the center of their education and that learning should occur in a familiar context that attends to multiple ways of thinking. 
104 Multicultural Educational Practices: School Women Leaders Perspectives and Contextual Realities for Promoting Intercultural Harmony in Schools

Nowadays, educationists believe that injecting multicultural content in the formal curriculum and in diverse school programmes is essential since children begin to detect differences and develop racial, tribal, ethnic prejudices at a very early age (DermanSparks, 1989).

Regarding the Research Literature on Approaches to Promoting Intercultural Harmony cotton 1993 were examined Ninty one documents . Fifty-five of these are research documents concerned with the impact of various schooling practices on the intercultural knowledge, attitudes, and/or behavior of teachers and students. Another 36 are related research or research-based documents--demographic studies, position papers, inquiries into the nature of prejudice, program descriptions, and discussions of differing cultural traits and learning styles. The research literature on cultural diversity is itself very diverse. Of the 55 research reports on approaches to improve intercultural relations, 32 are studies or evaluations, 21 are reviews or syntheses, and 2 summarize both review and study efforts.

Subjects in 43 of the reports are students (1 preschool/kindergarten, 14 elementary, 7 secondary, 3 postsecondary or other adult, and 18 general elementary-secondary or unspecified student population). Pre service teachers are the subjects of 5 of the reports, and in service teachers are the subjects in 4. While 16 of the reports focusing on students do not specify the cultural groups to which the ir subjects belong (describing them only as "culturally diverse" or "culturally mixed"), the other 27 documents do identify the groups their subjects represent.. Others identify the ir subjects by specific background Some of this research also studied the differential effects of certain schooling practices on males versus females and disabled versus able-bodied subjects. Looking at the research on pre service and in service teachers, four of these studies indicated only that their subjects were culturally diverse, but groups specified in the other 5 studies included white or Anglo (5 studies), black or African-American (3), and Hispanic (2). (cotton, 1993)

So this research is aimed to find out the views and perceptions of specially women who are heading their schools/institutes about the inter-cultural education system. It also tends to raise question about the different school practices, if any, to promote and encourage the inter-cultural practices in normal teaching-learning process. Through this research a view about the posed challenges will also get clear associated to the implementation and integration of inter-cultural harmony and education at school and what are the programmes that school design in order to guide their teachers about this concept. 


\section{Research Questions}

This research study looks to present the answers of the following questions;

1. How does a school women head perceive the concept of "inter-cultural education"?

2. What school practices promote inter-cultural practices in routine teaching-learning processes?

3. What training programmes does the school offer its teachers regarding inter-cultural education?

4. What are the different challenges associated with the implementation and integration of inter-cultural education at school?

\section{Research Methodology}

Altogether 30 School women leaders were selected through purposive-random sampling from a sample of 30 private schools of Karachi selected with the help of convenient sampling. The most experienced School women leaders were focused for this study. The perspective of School leadership regarding Multicultural Education and their practices in everyday schooling was collected through interviews by using an open ended questionnaire so the study is completely qualitative in nature. At the end, the collected data was analyzed by qualitative theme analysis. The theme analysis of qualitative data was done.

\section{Data Analysis}

The classification and cross-referencing of respondents' qualitative input in the questionnaire and the observations of interviews in general indicate that this data can be categorized into distinct heads and sub-heads. Use of naturalistic generalization allowed developing generalizations that people can learn from the case (Creswell, 1998). The details of data analysis are as follows;

\section{i. Activities in Schools for Promoting the Understanding of Cultures}

\section{a. Organizing events, festivals and awareness raising campaigns of multicultural themes}

Analysis reveal that a number of schools regularly organize events that help the stakeholders in developing a better understanding of multiple cultures and therefore share their values. However, this has been tagged as an area of concern by some schools as well.

\section{b. Celebrating holidays of different cultures}

According to the data collected from the school heads, the different cultural events and holidays are accordingly celebrated at school level in either an express or implied form depending upon the nature and magnitude of the occurrence. 
106 Multicultural Educational Practices: School Women Leaders Perspectives and Contextual Realities for Promoting Intercultural Harmony in Schools

c. Showcasing arts, crafts, literature, cuisines, music, sports and other cultural identities

Almost all the school principals promote and pay homage to the cultural values at school level by showcasing multicultural art, literature, music, sports etc.

\section{ii. Role of School Women Leadership and Management}

\section{a. Enriching curriculum with intercultural knowledge}

A handful of school leaders indicate that curriculum enrichment practices in their schools also encompass the consideration of cultural aspects in the process. On the other hand, this area is considered a challenge by the majority of the principals.

\section{b. Implementing intercultural educational components at classroom level}

Almost all the principals realize the importance of intercultural respect and sharing of values at school level. In this regard, the school heads have introduced strong monitoring mechanisms for ensuring that teachers ensure the integration of intercultural educational components at classroom level.

\section{c. Promoting the use of teaching aids and resources that reflect multicultural} aspects

Teaching aids and learning resources can also be used to promote multicultural values in school education. A few school heads also highlighted that they have low-cost resources and teaching aids that reflect the shades of different cultures of the society for promoting and understanding of intercultural harmony.

\section{iii. Organizing Stakeholder Learning Programs for Multicultural Integration}

\section{a. Promoting organizational learning for intercultural harmonization in school personnel}

Some vastly experienced women principals pointed out that they had prioritized and implemented the essentials of organizational learning for the continuous and holistic capacity enhancement of the school employees. According to the school heads cultural congruence was also a major part of this approach.

\section{b. Customizing teacher training programmes for multi cultur all knowledge acquisition}

Inducing female teachers to opt for intercultural learning has been identified as a major challenge by the school heads. Although a number of workshops and training programs have been attended by the school teachers encompassing the thematic areas of multiculturalism and education but it has not been translated into sharing. 


\section{c. Building capacities of communities and partner organizations to create knowledge and develop the skills and attitudes towards intercultural sharing}

Just a few have gone for a holistic stakeholder approach involving students, teachers, staff, parents and communities in promoting and better understanding the conceptual paradigms of multicultural education. On the other hand this area has been identified as a major challenge by majority of the school heads as they do not seem to have the resources or enough experience to implement such a system.

\section{Conclusions and Recommendations}

The core focus of this qualitative study was to understand the perspectives of school women principals while highlighting the contextual realities when it comes to intercultural harmony and multicultural education at school level. The generalized conclusion drawn from this study indicate that there is a strong will of school female heads to integrate intercultural practices but there is not adequate expertise and experienced personnel at school management level to impart multicultural education in the holistic framework of any school. As indicated in the data analysis, scattered efforts in varied thematic areas, although positive for conceptual promotion, cannot be holistically effective.

At the same time, this research case also identifies the need for further research with a more diverse sample or by involving more stakeholders from various ethnicities, creeds and backgrounds. In addition to that the time frame of the research study can also be lengthened to yield more concrete findings. Furthermore, this research was designed as a qualitative study, using in-depth interviews and observations with the school heads. Adding a quantitative perspective, surveys and check lists, might provide further insight for examining multicultural practices in schools. School Environment and class room environment should be provided to enhance critical thinking skills of students to minimize the cultural, ethnic and racial discrimination among all tiers of studies through activities. School and class room displays must depict representation from all the ethnic, social and cultural diversities to promote inter-cultural system in schools. A sense of responsiveness must be generated among students with in class room environment, and through exercises outside the premises of school where they respect and regard others point of view and listen to them carefully. A concept of intellectual honesty must be promoted among the students where they readily accept an argument with enough evidences, though it may contradict with their own personal beliefs. Encourage in depth cross cultural participations should be promoted outside the class room and school. Promote and engage positive interaction among parents especially deemed for those areas where multi-cultural diversities exist. Teachers, leaders and management personnel who are directly linked with academics should be part of 
108 Multicultural Educational Practices: School Women Leaders Perspectives and Contextual Realities for Promoting Intercultural Harmony in Schools

activities/trainings to encourage inter-cultural diversities in areas where such differences are at peak.

\section{References}

BANKS, J.A. (1997) Educating citizens in a multicultural society. New York: Teachers College Press.

BANKS, J.A. (1999). An introduction to multicultural education. Boston: Allyn\& Bacon.

Banks, J.(2008). An Introduction to Multicultural Education. 4th. edition. Pearson, Allyn /Bacon.

BENETT, C.I. (2003). Comprehensive multicultural education: Theory and practice (5th ed.). Boston: Allyn and Bacon.

Darling-Hammond, L. (2006).Powerful teacher education. Lesson from exemplary programs. San Francisco: Jossey-Bass.

DERMAN-SPARKS, L. (1989).Anti-bias curriculum: Tools for empowering young children. Washington, DC: National Association for the Education of Young Children.

GORSKI, P.C. (2001). Mission and purpose. St. Paul, MN: Ed Change Multicultural Pavilion. Available at: www.edchange.org/multicultural/mission.html.

Kincheloe, J. L., \& Steinberg, S. R. (1997).Changing multiculturalism. Buckingham: Open University Press.

NIETO, S. (2000).Affirming diversity: the sociopolitical context of multicultural education, (3rd ed.). New York: Longman.

Parrenas, F. Y., and Parrenas, C. S.( 1990.)Cooperative Learning, Multicultural Functioning, and Student Achievement. SanBernardino, CA: San Bernardino School District, (ED 337 540)

Ploumis- Devick, E.( 1992). Appreciating Differences: Teaching and Learning in a Culturally Diverse Classroom. Hot Topics: Usable Research Series. Greensboro, NC: South Eastern Regional Vision for Education (SERVE) 
Sales, A. y García, R. (1997).Programas de Educación Intercultural. Bilbao: Desclée De Brouwer.

SLEETER, C.E., \& Grant, C.A. (1988).Making choices for multicultural education: Five approaches to race, class, and gender. Columbus, $\mathrm{OH}$ : Merrill Publishing Company.

School Improvement Research Series ,Fostering Intercultural Harmony in Schools: Research

Cotton Kathleen, 1993. "Retrieved from Fostering Intercultural Harmony in Schools: Research Finding", retrieved

from http://educationnorthwest.org/webfm_send/522

Sleeter, E. E., and Grant, C. A. (1987)."An Analysis of Multicultural Education in the United States."Harvard Educational Review 57/4: 421-444.

Joe L. Kincheloe and Shirley R. Steinberg, Peter McLaren, Henry Giroux, Antonia Darder, Christine Sleeter, Ernest Morrell, Sonia Nieto, Rochelle Brock, Cherry A. McGee Banks, James A. Banks, Nelson Rodriguez, Leila Villaverde and many other scholars of critical pedagogy have offered an emancipatory perspective on multicultural education.

http://en.wikipedia.org/wiki/Multicultural_education

Tayyaba Zarif is Associate Professor \& Head of the Department of Education in Newports Institute of Communication and Economics Karachi.

Aziz - un- Nisa is Assistant Professor in Department of Education, University of Karachi. 